\title{
Crizotinib-associated toxic epidermal necrolysis in an ALK-positive advanced NSCLC patient
}

\author{
SHAOYU YANG ${ }^{1}$, LIMING WU $^{2}$, XIN LI $^{1}$, JIE HUANG $^{1}$, JIANBO ZHONG $^{2}$ and XUEQIN CHEN ${ }^{1}$ \\ Departments of ${ }^{1}$ Medical Oncology and ${ }^{2}$ Dermatology, Hangzhou First People's Hospital, \\ Nanjing Medical University, Hangzhou, Zhejiang 310006, P.R. China
}

Received August 29, 2017; Accepted November 11, 2017

DOI: $10.3892 / \mathrm{mco} .2018 .1553$

\begin{abstract}
Crizotinib is an oral small-molecule inhibitor of anaplastic lymphoma kinase (ALK) tyrosine-kinase that has been approved for treating patients with advanced echinoderm microtubule associated protein like 4-ALK rearranged non-small-cell lung cancer (NSCLC). Toxic epidermal necrolysis (TEN) is a rare adverse event associated with crizotinib. The present study reported a case of a 75-year-old Chinese male patient with advanced NSCLC with ALK fusion, who developed TEN after 56 days of crizotinib treatment and demised due to this dermatological adverse event. The occurrence of severe cutaneous necrolysis that predominantly involves the skin and mucous membranes during crizotinib treatment should alert clinicians to be aware of TEN and take prompt actions.
\end{abstract}

\section{Introduction}

Non-small-cell lung cancer (NSCLC) with echinoderm microtubule associated protein like 4-anaplasitic lymphoma kinase (EML4-ALK) rearranged has been found to highly respond to crizotinib, an oral small-molecule ALK tyrosine-kinase inhibitor (1). Cizotinib is generally well tolerated, which most common adverse events include visual dysfunction (60\%), nausea $(55 \%)$, vomiting (47\%), diarrhea (60\%), and pitting edema (31\%) (1). Severe skin involvement is comparatively rare reported for cizotinib (2). Here we firstly report a case of crizotinib-associated toxic epidermal necrolysis (TEN).

Correspondence to: Dr Xueqin Chen, Department of Medical Oncology, Hangzhou First People's Hospital, Nanjing Medical University, 261 Huansha Road, Hangzhou, Zhejiang 310006, P.R. China

E-mail: chenlucy1437@aliyun.com

Key words: crizotinib, toxic, epidermal, necrolysis, non-small-cell lung cancer

\section{Case report}

A 75-year-old Chinese male was admitted to our hospital for non-productive cough and progressive dyspnea in April 2016. Confirmed by the tumor biopsy, he was diagnosed as adenocarcinoma lung cancer with pleura and osseous metastasis (T2NxM1c). As the chromosomal fusion of EML4-ALK was detected by amplification refractory mutation system, first-line treatment with crizotinib was started on May 11th 2016. One month later, pulmonary CT scan suggested that the disease was stable, whereas the patient was admitted to hospital again for hepatic insufficiency and edema of lower extremity, which both were due to crizotinib. Reduced glutathione and magnesium isoglycyrrhizinate were administered for liver protection, and furosemide was administered to promote diuresis. On July 6th, 56 days after initiation of crizotinib treatment, the patient suddenly developed skin rash presenting as itchy papules on the trunk without symptom before or simultaneously skin eruption. The rash quickly became diffuse papules with vesicles, which progressed to flaccid bullae. Moreover, the patients developed oral ulcers and conjunctivitis. Skin biopsy was performed after consulting the dermatologist. Histopathological analysis suggested various cutaneous changes (Fig. 1A and B). In the epidermis, a large number of cells showed eosinophilic degeneration, swelling and necrosis, with unclear cell boundary, karyopyknosis or karyolysis. Multiple vacuoles and fissures were also observed inside the epidermis. Besides, some cells of the basal layer showed liquefactive degeneration. The epidermis-dermal junction was not clear and present interface dermatitis changes. Moreover, in the upper and middle dermis, perivascular inflammatory cells infiltration and erythrocyte overflew were detected. A diagnosis of Stevens-Johnson syndrome (SJS) was made. Written informed consent was obtained from the patient and the present study was approved by the Institutional Ethics Committee of Hangzhou First People's Hospital.

Crizotinib was immediately discontinued and the patient received dexamethasone (5 $\mathrm{mg}$, i.v., daily), cetirizine and topical steroids. Five days later, the patient's condition deteriorated with a fever of above $38.5^{\circ} \mathrm{C}$, as well as diffuse rash expanded to the limbs and face. At last, the affected area reached $>50 \%$ of his body surface, and the patient was diagnosed as TEN, according to the quantitative evaluation of the surface of affected skin. The patient was then treated 

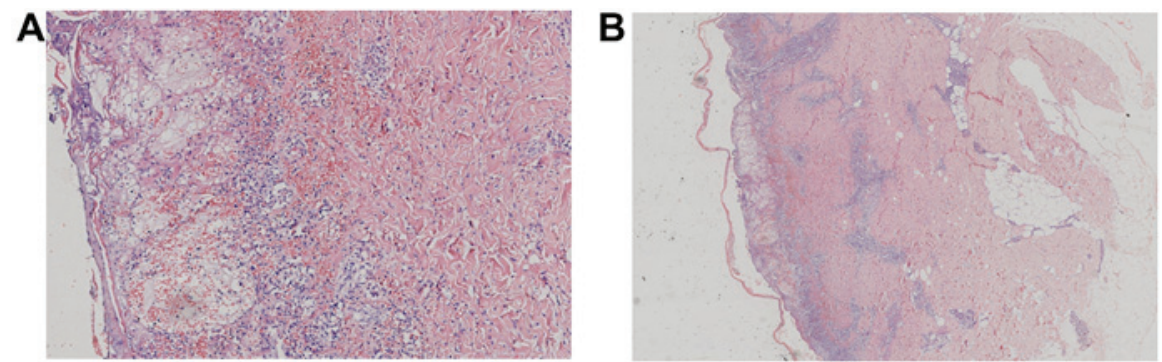

Figure 1. Histopathological findings. H\&E staining, (A) original magnification, x100. (B) original magnification, x20.
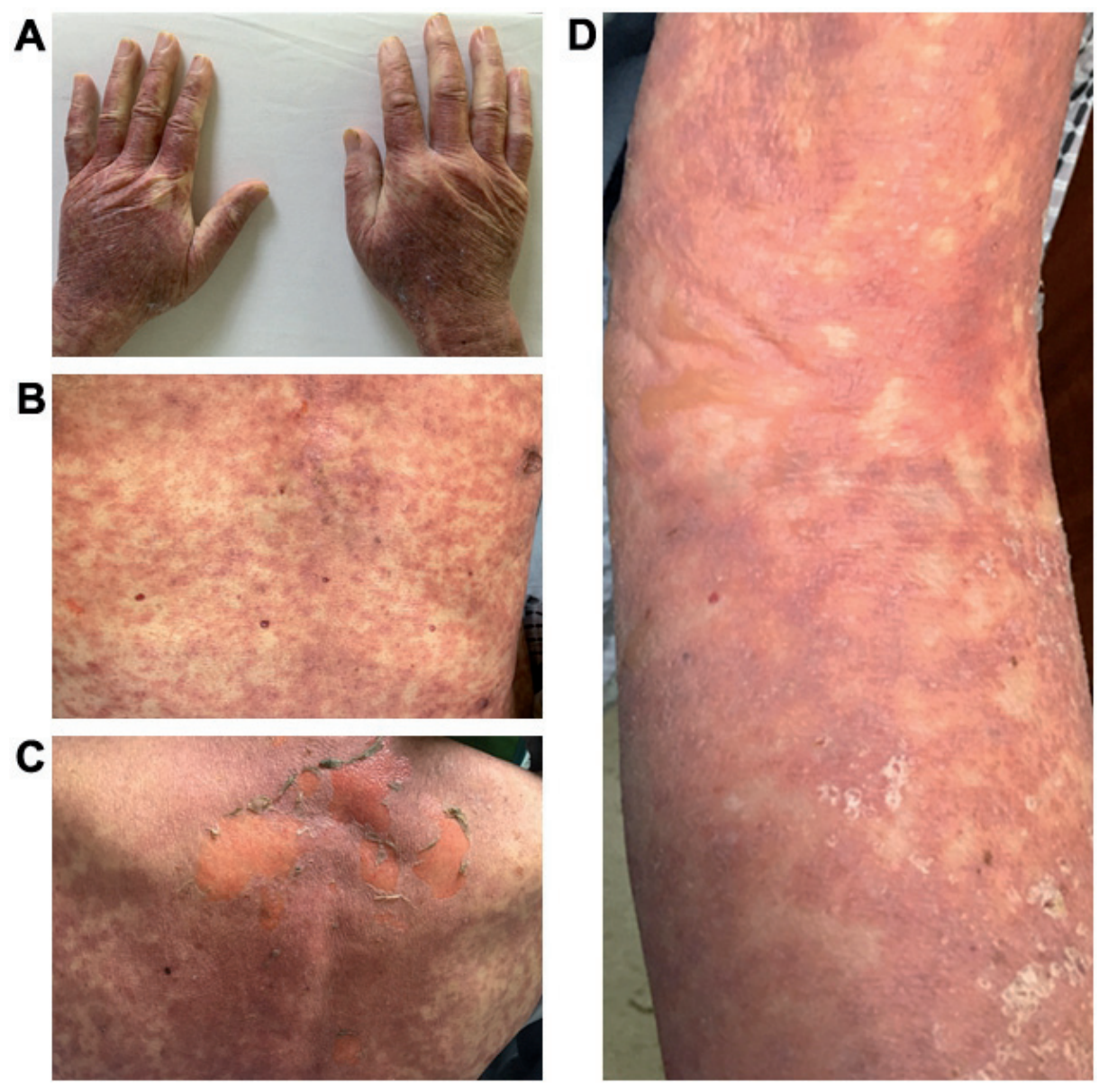

Figure 2. TEN associated with crizotinib treatment. (A) Hands, (B) chest, (C) back and (D) arm.

with methylprednisolone (40 mg i.v. bid), intravenous Human Normal Immunoglobulin (20 g i.v. gtt qd) and anti-infective therapy. However, his symptoms was not relieved after 10 days of treatment, and the skin lesions still progressed quickly (Fig. 2), Nikolski sign was present (Fig. 2C). The patient died 22 days after the discontinuation of crizotinib.

\section{Discussion}

Crizotinib is a clinically available ALK inhibitor, with previously reported severe adverse events majorly including esophageal ulcer (3), diffuse alveolar damage (4), and erythema multiforme (2). Up to date, only two cases of SJS were reported which were developed after single molecule targeted therapy acting against the EGFR (epidermal growth factor receptor) and ALK, both were related with afatinib $(5,6)$.

To our knowledge, this case is the first report of crizotinib-associated TEN. SJS and TEN are two overlapping syndromes of burning-like severe skin lesions and characterized by skin detachment. Both syndromes are life-threatening skin conditions, with mortality rates of $1-10 \%$ for SJS and 20-40\% for TEN (7). The only differentiate criterion for the two syndromes is the quantitative evaluation of the range of affected skin. For SJS, the affected skin area is less than $10 \%$ of Total Body Surface Area (TBSA), whereas the proportion is $>30 \%$ for TEN. If the skin involvement ranges between 10 to $30 \%$, it is defined as overlapping syndrome (7). The most well-known causes for the above syndromes are certain medications, but in very rare cases, the coexistence of 
cancer can also have an impact on the incidence of SJS and TEN (7). Several cutaneous adverse cases have also recently been reported while more and more immune checkpoint inhibition were used in cancer treatment $(8,9)$.

The diagnosis of SJS or TEN is mainly based on clinical parameters during the acute phase. In our case, keratinocyte apoptosis followed by necrosis is the pathogenic cause of the widespread epidermal detachment observed in this patient. Since the patient have not taken any other suspicious drugs beside crizotinib, both before and during the development of skin lesions, we consider TEN was most likely induced by crizotinib. It was reported that Blacks and Asian patients were at a higher risk than Caucasian (10). Some researchers found a strong association between HLA genotype and SJS/TEN in Han Chinese $(11,12)$. In this case, it happened more than 1 month after the causative drug was initiated, and because of its potential increased mortality we should try to find TEN predict factors before crizotinib treatment.

In conclusion, clinicians should be aware of SJS and TEN during the usage of crizotinib in NCSLC patients, when patients develop symptoms including generalized skin rash followed by a few flaccid bullae, separation of large sheets of epidermis from the dermis, and mucositis of the mouth and genital area. Immediate crizotinib discontinuation and adequate treatment of skin diseases are required in these cases.

\section{Acknowledgements}

The present study is supported by funding from the Health Foundation of Hangzhou City Zhejiang Province (grand no. 2015 Z003).

\section{Competing interests}

The authors declare that they have no competing interests.

\section{References}

1. Shaw AT, Kim DW, Nakagawa K, Seto T, Crinó L, Ahn MJ, De Pas T, BesseB, Solomon BJ, Blackhall F, et al: Crizotinib versus chemotherapy in advanced ALK-positive lung cancer. N Engl J Med 368: 2385-2394, 2013.

2. Sawamura S, Kajihara I, Ichihara A, Fukushima S, Jinnin M, Yamaguchi E, Kohrogi $\mathrm{H}$ and Ihn $\mathrm{H}$ : Crizotinib-associated erythema multiforme in a lung cancer patient. Drug Discov Ther 9: 142-143, 2015.

3. Park J, Yoshida K, Kondo C, Shimizu J, Horio Y, Hijioka S and Hida T: Crizotinib-induced esophageal ulceration: A novel adverse event of crizotinib. Lung Cancer 81: 495-496, 2013.

4. Tamiya A, Okamoto I, Miyazaki M, Shimizu S, Kitaichi M and Nakagawa K: Severe acute interstitial lung disease after crizotinib therapy in a patient with EML4-ALK-positive non-small-cell lung cancer. J Clin Oncol 31: e15-e17, 2013.

5. Doesch J, Debus D, Meyer C, Papadopoulos T, Schultz ES, Ficker JH and Brueckl WM: Afatinib-associated Stevens-Johnson syndrome in an EGFR-mutated lung cancer patient. Lung Cancer 95: 35-38, 2016.

6. Honda Y, Hattori Y, Katsura S, Terashima T, Manabe T, Otsuka A and Miyachi Y: Stevens-Johnson syndrome-like erosive dermatitis possibly related to afatinib. Eur J Dermatol 26: 413-414, 2016.

7. Rosen AC, Balagula Y, Raisch DW, Garg V, Nardone B Larsen N, Sorrell J, West DP, Anadkat MJ and Lacouture ME: Life-threatening dermatologic adverse events in oncology. Anticancer Drugs 25: 225-234, 2014

8. Vivar KL, Deschaine M, Messina J, Divine JM, Rabionet A, Patel N, Harrington MA and Seminario-Vidal L: Epidermal programmed cell death-ligand 1 expression in TEN associated with nivolumab therapy. J Cutan Pathol 44: 381-384, 2017.

9. Collins LK, Chapman MS, Carter JB and Samie FH: Cutaneous adverse effects of the immune checkpoint inhibitors. Curr Probl Cancer 41: 125-128, 2017.

10. Frey N, Jossi J, Bodmer M, Bircher A, Jick SS, Meier CR and Spoendlin J: The epidemiology of Stevens-Johnson syndrome and toxic epidermal necrolysis in the UK. J Invest Dermatol 137: 1240-1247, 2017

11. Man CB, Kwan P, Baum L, Yu E, Lau KM, Cheng AS and Ng MH: Association between HLA-B*1502 allele and antiepileptic drug-induced cutaneous reactions in Han Chinese. Epilepsia 48: 1015-1018, 2007.

12. Chung WH, Hung SI, Hong HS, Hsih MS, Yang LC, Ho HC, Wu JY and Chen YT: Medical genetics: A marker for Stevens-Johnson syndrome. Nature 428: 486, 2004. 